\title{
Article \\ Trapping of Ceratitis capitata Using the Low-Cost and Non-Toxic Attractant Biodelear
}

\author{
Nikos A. Kouloussis ${ }^{1}$, Vassilis G. Mavraganis ${ }^{2}$, Petros Damos ${ }^{1}$, ${ }^{\text {, Charalampos S. Ioannou }}{ }^{3}$, \\ Eleftheria Bempelou ${ }^{4}\left(\mathbb{D}\right.$, Dimitris S. Koveos ${ }^{1}$ and Nikos T. Papadopoulos ${ }^{3, *}$ (i)
}

1 Laboratory of Applied Zoology and Parasitology, School of Agriculture, Aristotle University of Thessaloniki, 54124 Thessaloniki, Greece; nikoul@agro.auth.gr (N.A.K.); petrosdamos@gmail.com (P.D.); koveos@agro.auth.gr (D.S.K.)

2 Hellenic Agricultural Organization-DEMETER, Institute of Soil and Water Resources, S. Venizelou 1, Lykovrissi, 14123 Athens, Greece; mavrag1a@otenet.gr

3 Laboratory of Entomology and Agricultural Zoology, Department of Agriculture Crop Production and Rural Environment, University of Thessaly, Phytokou St., 38436 Volos, Greece; ioannoubabis@yahoo.com

4 Pesticide Residues Laboratory, Benaki Phytopathological Institute, St. Delta 8, Kifissia, 14561 Athens, Greece; e.bempelou@bpi.gr

* Correspondence: nikopap@uth.gr

Citation: Kouloussis, N.A.; Mavraganis, V.G.; Damos, P.; Ioannou, C.A.; Bempelou, E.; Koveos, D.S.; Papadopoulos, N.T. Trapping of Ceratitis capitata Using the Low-Cost and Non-Toxic Attractant Biodelear. Agronomy 2022, 12, 525. https:// doi.org/10.3390/agronomy12020525

Academic Editor: Angelo Canale

Received: 31 December 2021

Accepted: 14 February 2022

Published: 20 February 2022

Publisher's Note: MDPI stays neutral with regard to jurisdictional claims in published maps and institutional affiliations.

Copyright: (C) 2022 by the authors. Licensee MDPI, Basel, Switzerland. This article is an open access article distributed under the terms and conditions of the Creative Commons Attribution (CC BY) license (https:// creativecommons.org/licenses/by/ $4.0 /$ )
Abstract: Trapping is considered a powerful tool in the monitoring and control of fruit flies of high economic importance such as the Mediterranean fruit fly, Ceratitis capitata (Diptera: Tephritidae). However, the cost of trapping and, in some cases, the safety of the chemicals used as baits are concerning for growers and the environment. Here we present a novel, low cost, environmentally friendly, female-specific bait for C. capitata, called Biodelear, that consists of a mixture of attracting compounds such us pyrazines, pyranones and amorphous nitrogen-based polymers. The new bait was compared to the commercially available attractant Biolure ${ }^{\circledR}$ (Suterra LLC, Bend, OR, USA) in Greece. McPhail-type traps were deployed in an orange orchard located in Athens. Five traps per treatment were used for several weeks during 2009 and four traps per treatment in 2010. Traps contained either $17 \mathrm{~g}$ of Biodelear or one Biolure Unipack dispenser. The results showed that both baits were highly efficient in attracting $C$. capitata females, and to a lesser extent, males. Although Biolure initially appeared to outperform Biodelear, later in the season the two attractants converged in efficacy. In both years, female captures were similar in traps baited with Biolure and Biodelear. However, male captures were higher in Biodelear-baited traps in 2010. In addition, Biodelear seemed to be longer lasting than Biolure, despite not being formulated into a slow-release dispersion system. The low cost of Biodelear and its strong, long-lasting effects render it suitable for mass trapping of the Mediterranean fruit fly.

Keywords: fruit flies; Diptera; Tephritidae; Mediterranean fruit fly; medfly; bait; trapping; IPM; sustainability; attractants; lures; lure and kill

\section{Introduction}

Pest management strategies are inseparably linked to detection and population monitoring of the target population with adult trapping being by far the most effective, simple and reliable tool used for achieving them [1-3]. Trapping can also serve as a control method by itself, aiming to mass-trap the pest insect and thus reduce its population bellow economic injury levels [4,5]. The development of mass-trapping devices (traps) and the discovery of novel powerful attractants comprises a large part of entomological research [6,7]. Modern technologies involve advanced trapping systems which are long lasting, easy-to-use, powerful, and selective for the target insect pest [8]. However, the commercially available lures, which are highly efficient, are at the same time rather costly. As a result, there are cases where the economic viability of mass trapping is questioned because the high density of traps required may be too expensive to implement [9-13]. 
The Mediterranean fruit fly (medfly), Ceratitis capitata (Wiedemann) (Diptera: Tephritidae) is one of the most destructive insect pests worldwide [14]. Infesting more than 300 fruit and vegetable species and having a cosmopolitan geographic distribution that is ever expanding, medfly exerts a direct economic loss to growers and dramatically affects national and international fruit commerce [15-18]. If medfly populations are not managed, infestation often exceeds $50 \%$ of the total fruit produce and in 'preferred' hosts, infestation may reach $100 \%$. Moreover, it is considered among the most aggressive invasive species threatening fresh fruit production in areas well beyond its current geographic distribution [19-21]. From the ancestral habitats of the east sub-Saharan Africa, medfly has dispersed first to Mediterranean countries and then to South and Central America, and Australia. Currently the fly is frequently detected in California, North America and central European countries [22,23]. Extensive detection and population monitoring projects relying on adult trapping have been implemented in several areas all over the globe [24-28]. Traditionally, attractants (baits) based on aqueous, proteinaceous solutions and/or fragmented sugar, were used to attract adult medflies to food traps (usually in McPhail-type traps). These traps capture males and females of $C$. capitata as well as other non-target fruit flies and species of other taxa, including beneficials $[26,29,30]$. The first breakthrough in C. capitata trapping came in the early 1960s when the potent male attractant Trimedlure (tert-butyl 4 (and 5)-chloro-2-methyl-cyclo-hexane-1-carboxylate) was discovered [31-34]. Jackson traps baited with Trimedlure have been used worldwide for detecting and monitoring populations of $C$. capitata for several decades. It took almost four decades to reach another breakthrough in medfly trapping, the development of a powerful system to attract females based on food-related compounds $[4,25,35]$. This system is composed of three compounds, ammonium acetate, putrescine and trimethylamine, loaded separately in a sophisticated dispersion unit and is commercially available as Biolure ${ }^{\circledR}$ Unipack (Suterra LLC, Bend, OR, USA). These attractants, placed in McPhail-type traps, have proven very effective and medfly-specific in several tropical and temperate areas after extensive experimental trials coordinated by the International Atomic Energy Agency (IAEA) over a period of several years [25]. This system provides reliable information on population fluctuation and is also sensitive in detecting populations early in the season and under low population densities [36,37]. Following the development of the above system by R.R. Heath and his coworkers, similar products (e.g., Tripack ${ }^{\circledR}$ MFL; Kenogard SA, Ferag CC D TM ${ }^{\circledR}$, Barcelona, Spain) were developed and are used against the medfly [7,8,38-40].

The cost of the above systems is a major issue that restricts its use in developing bait stations and as a part of a lure and kill control technique [41,42]. Biolure costs approximately $€ 5$ per dispenser (in the Greek market, 2022) and a recent economic analysis showed that the cost of using it for mass trapping in citrus cultivations can exceed $€ 100$ per 0.1 ha per year [43]. This cost is prohibitively high for farmers, especially in developing countries. Therefore, despite the substantial progress made, there is still a need for developing inexpensive, long-lasting attractants for the Mediterranean fruit fly and other fruit flies.

Recent laboratory studies revealed that adult medflies and other fruit flies are strongly attracted to a novel environmentally friendly product named Biodelear after the ancient Greek words " $\beta \operatorname{lo\zeta }$ " (life) and " $\delta \varepsilon \dot{\lambda} \varepsilon \alpha \alpha$ " (lure, attract, entice, decoy). Biodelear is a liquid product of the Maillard reaction between fructose and urea. It consists of pyrazines, pyranones, heterogeneous amorphous polymers as well as other ingredients, which decompose slowly and release compounds attractive to fruit flies. Biodelear has a very low cost and no toxicity to the environment [44]. An economic analysis on the prospective use of Biodelear in citrus cultivations, using $17 \mathrm{gr}$ of Biodelear per trap, showed that the cost of mass trapping per 0.1 ha per year would be $€ 30$ if ten traps were used, with the attractant being replaced five times during the season [43]. In addition, in recent mass trapping experiments of $C$. capitata conducted in citrus orchards in the island of Chios, Greece, Biodelear appeared to be very effective to reduce fruit infestation when used in conjunction with plastic McPhail traps [45]. That work did not involve a direct comparison of Biodelear with the commercially available Biolure attractant. 
Reported herein are field studies testing the efficacy of Biodelear in capturing C. capitata compared to the standard Biolure trapping system that is widely used for monitoring and detecting medfly populations [46]. Our results show that Biodelear used in McPhail traps is as attractive and long-lasting while being inexpensive compared to Biolure.

\section{Materials and Methods}

\subsection{Field Sites}

Field trials were conducted in 2009 and 2010 in the arboretum of the Agricultural University of Athens Greece (37.9816940, 23.7071017). The climate of Athens is typical Mediterranean, classified as subtropical Mediterranean (Köppen Csa) [47]. The adult population of $C$. capitata peaks during summer and autumn [48,49]. The experimental orchard was about 0.8 to $1 \mathrm{ha}$, situated at $30 \mathrm{~m}$ above sea level. It comprised several citrus species (sweet oranges C. cinensis; sour oranges, C. aurantium; mandarin oranges, C. nobilis; lemons, Citrus limon; and grapefruits, C. paradisi) as well as certain other hosts and non-hosts.

\subsection{Traps and Attractants}

In all experiments we used the commercially available plastic McPhail-type trap, Anel (Figure 1; Anel Standard Co, Athens, Greece). This trap is composed of a transparent upper part and a yellow bottom part. Insects enter the trap through a 4-cm diameter opening in its lower part. To kill and retain the attracted flies, $300 \mathrm{~mL}$ of $10 \%$ aqueous propylene glycol solution was placed in the bottom of the trap in all treatments [50]. Each week the aqueous propylene glycol solution was replaced. Using these traps, we compared the newly developed attractant Biodelear to the standard Biolure Unipak formulation distributed in Greece by Hellafarm Ltd. (Athens, Greece). A flat $8.0 \times 5.0 \times 0.2 \mathrm{~cm}$ piece of sponge (Wettex, Athens, Greece) impregnated with Biodelear was placed in a small plastic basket suspended from the ceiling of the trap above its entrance. Biodelear was in a semi-viscus, water-soluble state and the amount required to saturate the sponge was $13.5 \mathrm{~mL}$ in volume (about $17 \mathrm{~g}$ in weight). The sponge was left to dry out before being suspended to the trap.

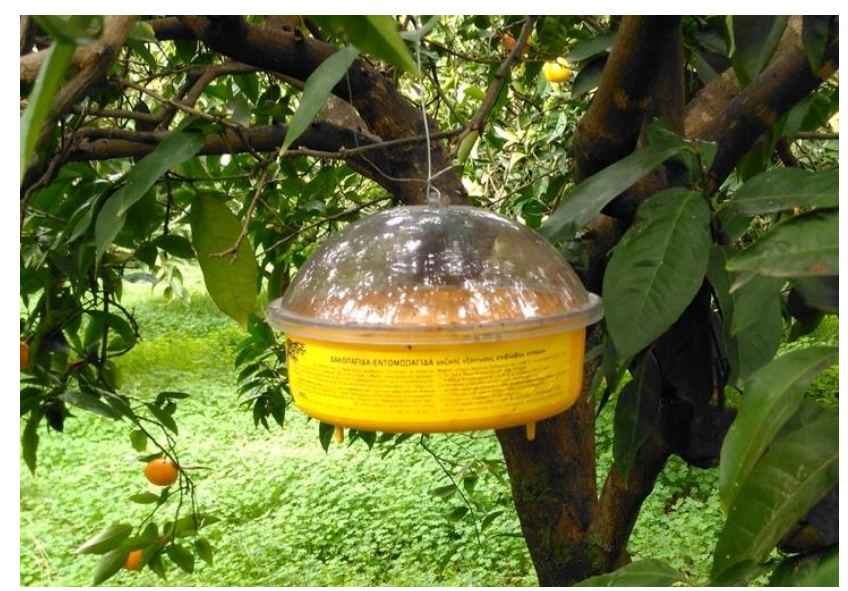

Figure 1. The McPhail type trap used in our trapping experiments to host both the Biodelear and the Biolure dispensers.

In all field trials, traps were deployed on 20 to 30-year-old sweet orange trees, planted $6 \mathrm{~m}$ apart. The traps were suspended in a shadowed part of the tree canopy at $\approx 1.8 \mathrm{~m}$ from the ground, and at a distance of $\approx 20 \mathrm{~m}$ from one another [50]. A randomized complete block experimental design was followed without trap rotation. Each block comprised one trap with Biodelear, one with Biolure and also one trap without any attractant to serve as a baseline (negative control). We used 5 blocks in 2009 and 4 blocks in 2010. Traps were checked every 1-3 days to a week, and captured flies were recorded and removed from the traps. 
The experiments conducted in 2009 were run from September to November and in 2010 from June to December. For comparative purposes, the results of 2010 were treated as two successive two-month periods (the first from June to August and the second from September to December). During the second trapping period we also tested the field aging of both attractants. Traps were installed on 22 June and were checked until the 6th of October (15 weeks period). Therefore, the same dispensers were used from June to October (June-September for the 1st test; September-December for the 2nd test). Additionally, on 26 August 2010 we set out four additional blocks baited with fresh dispensers of either Biolure or Biodelear in order to compare them with the old dispensers.

Because in each experiment, Biolure and Biodelear baited traps were treated in an identical manner, neither the different periods of running the field trials nor the timing of checking the traps affect the results. In fact, conducting tests at different times of the season and under high and low population densities contributes to a more comprehensive comparison of the two lures.

\subsection{Data Analysis}

To assess whether the lure (Biodelear, Biolure), the sex (Male, Female) and the date of capture were significant predictors, we used a generalized log-linear model (GLM's) assuming a Poisson distribution (better describes positive integral data and is often considered for data that violate linearity assumptions) with an overdispersion factor. Focusing on each sex and total captures, the effect of the lure on male, female and total (males + females) medfly captures was evaluated with a generalized log-linear model (GLM's) assuming a Poisson distribution with an overdispersion factor. The block was also included in the analysis since high variability among blocks was detected. A similar model was considered to evaluate the effect of new and old (field-aged dispensers) on captures of males, females and total. Analysis of variance was used to determine whether the type of lure and the date were significant predictors of the proportion of females (females/(male + female) captures) captured. All analyses were conducted using JAMOVI (www.jamovi.org, accessed 12 December 2021) software and R (RStudio 2013, Vienna, Austria) was used to plot graphs.

\section{Results}

\subsection{Performance of Biodelear in 2009}

In 2009 a total of 22,580 flies (86.5\% females) were captured throughout the experimental periods in traps baited with Biodelear, Biolure, and the negative control. Since only 521 flies were captured in the negative control this treatment was excluded from the statistical analysis. Overall, the number of adult captures was similar in traps baited with Biolure and Biodelear $\left(x^{2}=0,87 ; \mathrm{df}=1,384 ; p=0.376\right)$; however, the number of females attracted was higher than males $\left(x^{2}=765,2 ; \mathrm{df}=1,384 ; p<0.001\right)$. The date of capture was significant as well $\left(x^{2}=204,9 ; \mathrm{df}=23,384 ; p<0.001\right)$. All interactions between factors were non-significant $(p>0.05)$. Analysing captures of males and females separately, we found that traps baited with Biodelear and Biolure captured similar numbers of males $\left(x^{2}=1.97\right.$; $\mathrm{df}=1,230 ; p=0.161)$, females $\left(x^{2}=0.64 ; \mathrm{df}=1,230 ; p=0.422\right)$, and total number of adults $\left(x^{2}=0.91 ; \mathrm{df}=1,230 ; p=0.339\right)$, as depicted in Figure 2 . The variability among blocks was significant in all analyses $\left(x^{2}>12.96 ; \mathrm{df}=4,230 ; p<0.01\right)$, as well as the interaction between lure and block $\left(x^{2}=10.17 ; \mathrm{df}=4,230 ; p<0.05\right)$.

The proportion of females captured ranged from approximately 60 to $100 \%$ (Figure 3 ) and it was similar for the two lures (ANOVA, $x^{2}=1.2 ; \mathrm{df}=1,192, p=0.313$ ). The trapping date was a significant predictor of the proportion of females captured $\left(x^{2}=74.1 ; \mathrm{df}=23\right.$, $192, p<0.001)$ while the interaction date by lure was not $\left(x^{2}=25.6 ; \mathrm{df}=23,192, p=0.321\right)$. 

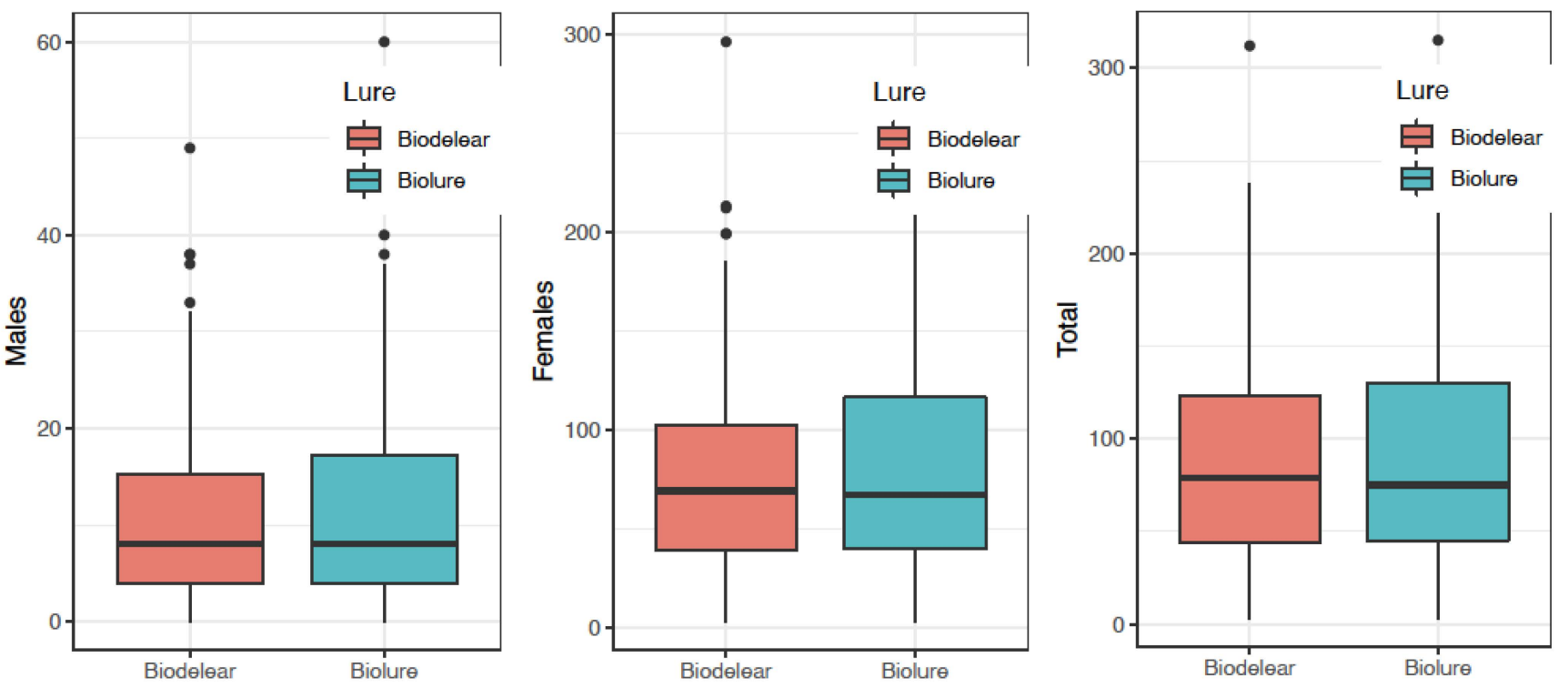

Figure 2. Boxplots (horizontal line $=$ medians, box $=$ quartiles, vertical line $=\mathrm{Q} 1-1.5 *$ (inter quartile range) and $\mathrm{Q} 3+1.5 * \mathrm{IQR}$, dots = outliers) depicting captures (per trap check) of males (left), females (centre) and total (right, males + females) medflies in trap checks conducted during October and November 2009 in traps baited with Biodelear and Biolure.

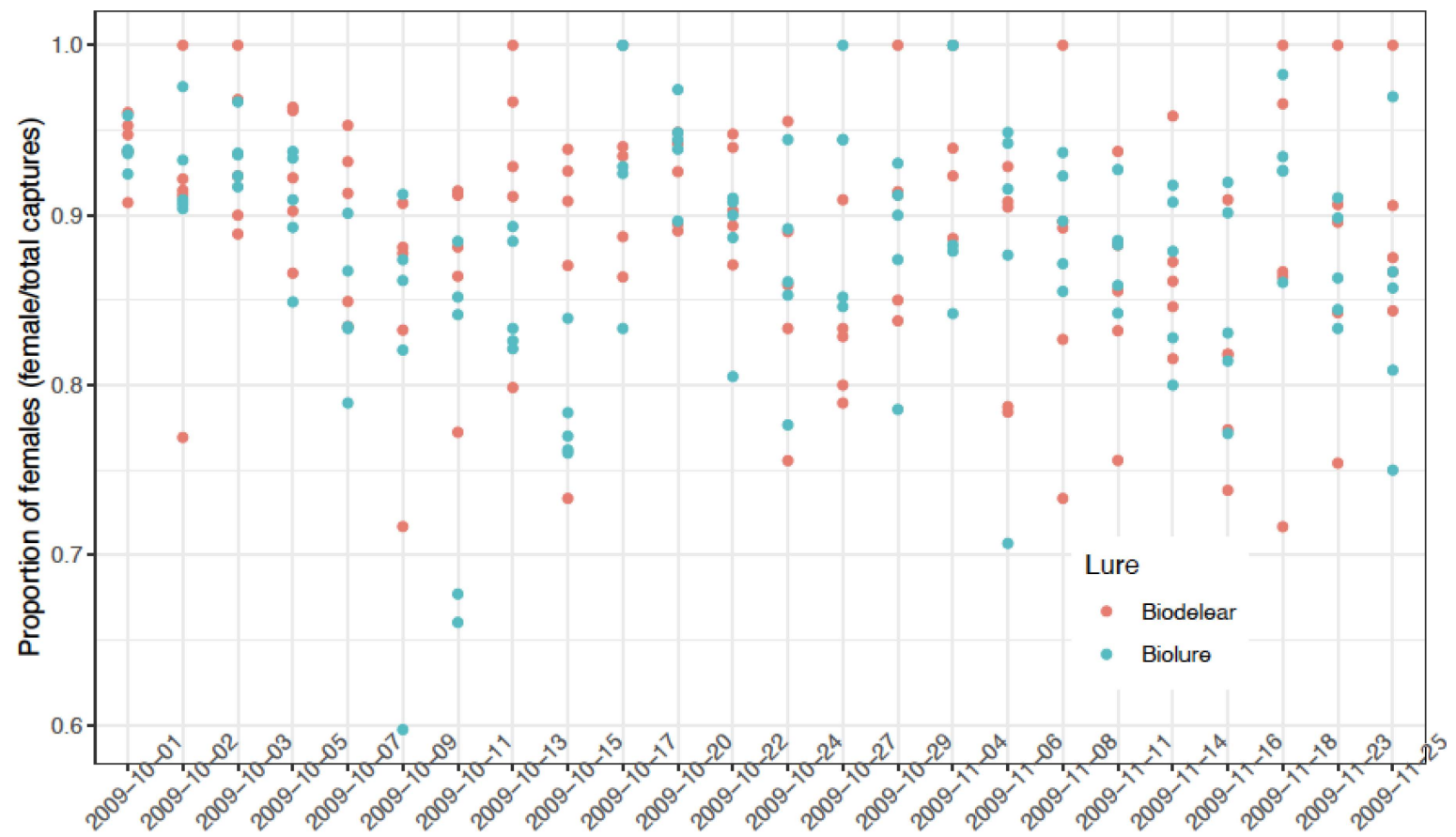

Figure 3. Proportion of female captures in traps baited with either Biodelear or Biolure during October and November 2009 in relation to the date of trap check.

\subsection{Performance of Biodelear in 2010}

In 2010, a total of 8214 flies ( $72.8 \%$ females) were captured throughout the experimental period that lasted almost four months. The number of captured flies in the negative control was very small (only 159 individuals) and this treatment was again excluded from the statistical analysis. Similar to 2009, sex and the date of trap check were significant predictors of adult captures $\left(x^{2}=3.95 ; \mathrm{df}=1,96 ; p=0.04 ; x^{2}=148.265 ; \mathrm{df}=7,96 ; p<0.001\right.$ respectively) while lure was not $\left(x^{2}=2.91 ; \mathrm{df}=1,96 ; p=0.09\right)$. All interactions were non-significant 
$(p>0.05)$ except for lure by trapping date $\left(x^{2}=16.5 ; \mathrm{df}=7,96 ; p=0.02\right)$. Analysing captures of males and females separately, we found that traps baited with Biodelear captured 2.7 times fewer males than Biolure $\left(x^{2}=5.32 ; \mathrm{df}=1,56 ; p=0.021\right.$; Figure 4). Block was a significant predictor of captures $\left(x^{2}=11.72 ; \mathrm{df}=3,56 ; p=0.008\right)$ while the interaction between lure and block was not significant $\left(x^{2}=2.01 ; \mathrm{df}=3,56 ; p=0.570\right)$. Traps baited with Biodelear and Biolure captured similar numbers of females $\left(x^{2}=2.31 ; \mathrm{df}=1,56 ; p=0.128\right)$. Block was a significant predictor of captures $\left(x^{2}=17.04 ; \mathrm{df}=3,56 ; p<0.001\right)$ while the interaction between lure and block was not significant $\left(x^{2}=0.989 ; \mathrm{df}=3,56 ; p=0.840\right)$. The total number of medfly captures was slightly higher in traps baited with Biolure compared with those baited with Biodelear $\left(x^{2}=4.02 ; \mathrm{df}=1,56 ; p=0.04\right)$. The variability among blocks was significant $\left(x^{2}=16.81 ; \mathrm{df}=3,56 ; p<0.01\right)$; however, the interaction between lure and block was not significant $\left(x^{2}=1.58 ; \mathrm{df}=3,56 ; p=0.66\right)$. Female selectivity was similar between the two attractants $\left(x^{2}, p<0.05\right)$.
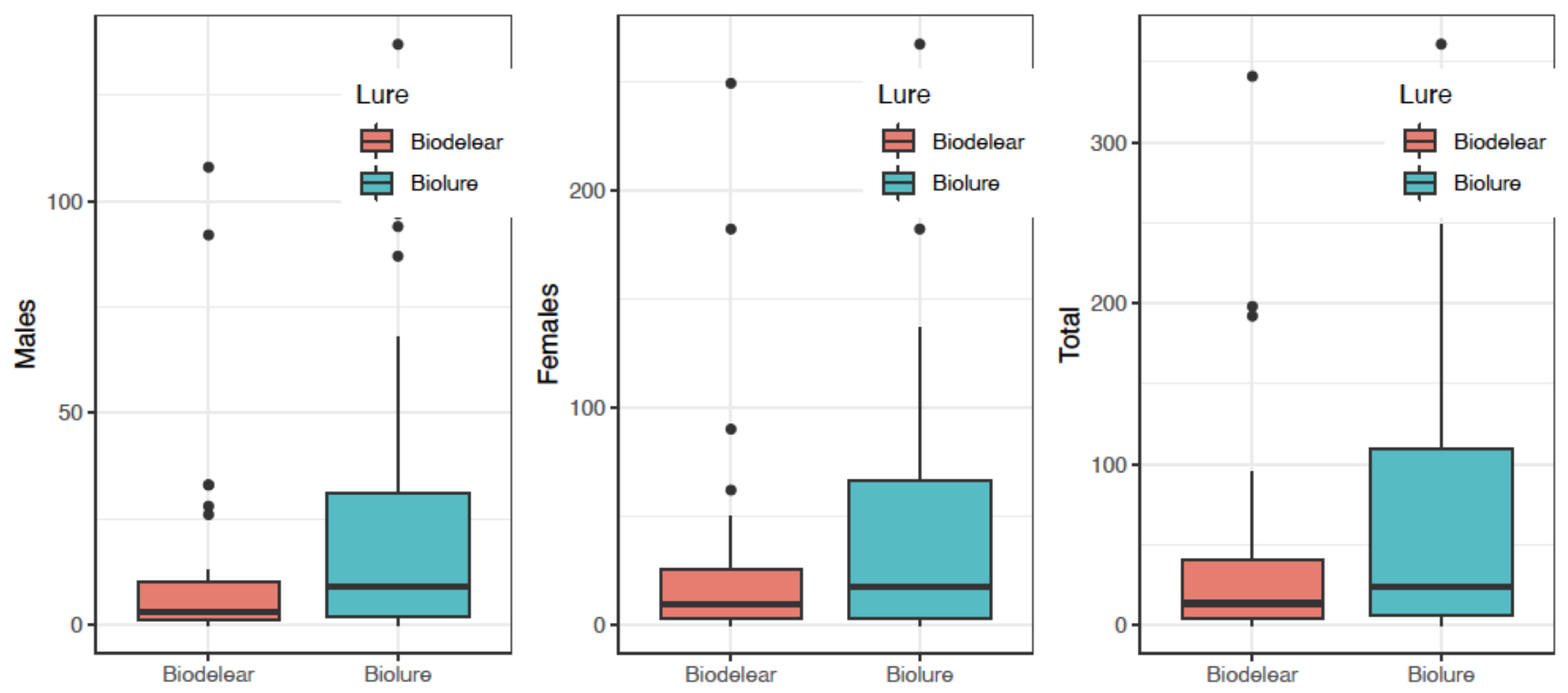

Figure 4. Boxplots depicting captures (per trap check) of males (left), females (center) and total (right, males + females) medflies in trap checks conducted during July and August 2010 in traps baited with Biodelear and Biolure.

\subsection{Field Aging of Biodelear in Trials Conducted in 2010}

The results of the field aging comparison are given in Figure 5 and demonstrate a clear difference between the old and the new dispensers in male, female and total captures $\left(x^{2}>35.61 ; \mathrm{df}=1,80 ; p<0.001\right)$. The new dispensers captured significantly higher numbers of flies than the old ones. Traps baited with fresh lures (either Biodelear or Biolure) captured 2.2 times more flies than those baited with old attractants. Overall (including old and fresh lures) the traps baited with Biolure captured more males $\left(x^{2}=27.31 ; \mathrm{df}=1,80 ; p=0.001\right)$, similar numbers of females $\left(x^{2}=3.23 ; \mathrm{df}=1,56 ; p=0.07\right)$ and higher numbers of males and females $\left(x^{2}=4.64 ; \mathrm{df}=1,56 ; p=0.031\right)$. In all analyses, block was a significant predictor of captures $(p<0.05)$, while lure by age of the dispenser and lure by block interactions were not significant $(p>0.05)$. 

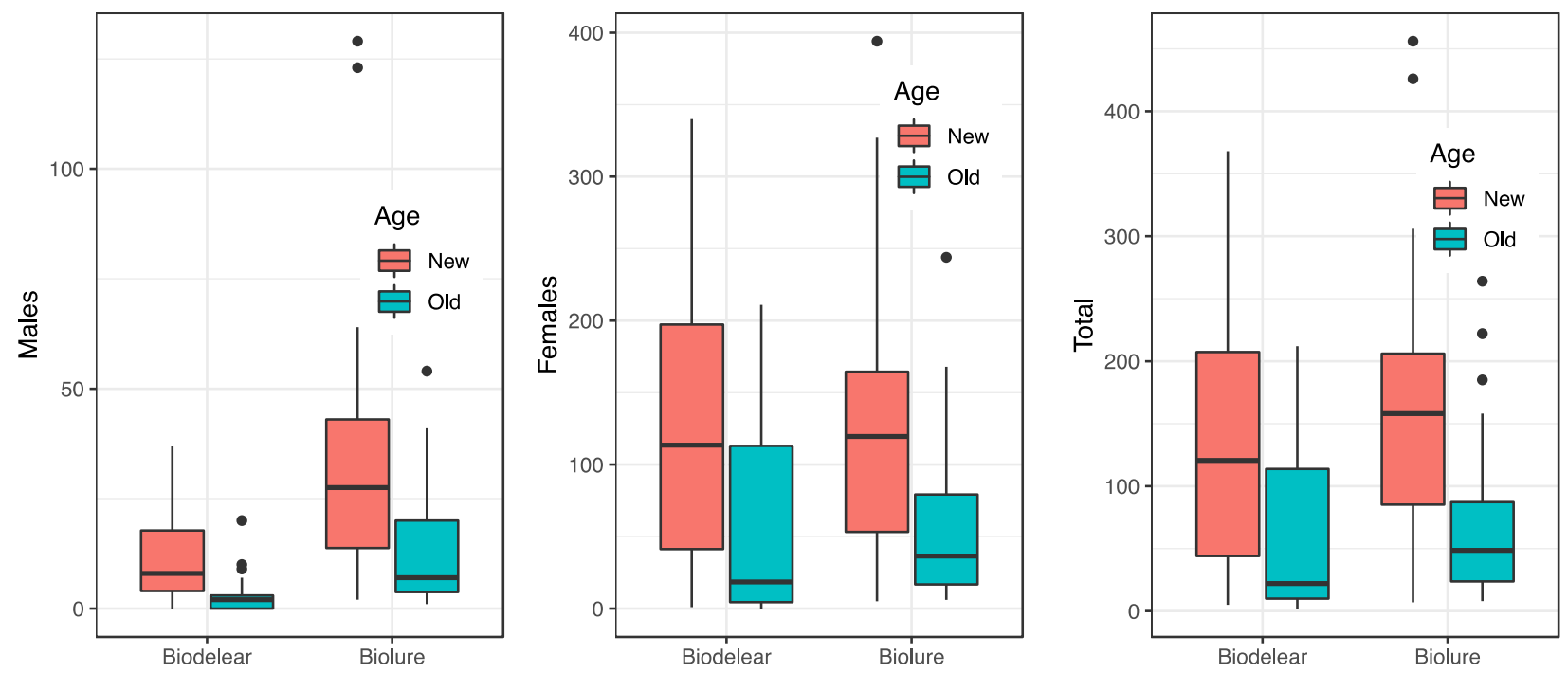

Figure 5. Box plots depicting the effect of the type (Biodelear, Biolure) and age of lure (New, Old) on captures of males (left), females (middle), and total (right) captures of adult medflies in field trials conducted in October and November 2010.

\section{Discussion}

The results of the present study demonstrate that the new low cost bait Biodelear [44] is very effective in attracting $C$. capitata adults and in particular females. Biodelear performed satisfactorily and in most cases proved equally effective to the commercially available product Biolure. In fact, except for the beginning of the second experimental year, when Biodelear attracted fewer females than Biolure, overall, the two baits had a comparable performance. Evidently, the population size was different in the two years. Various factors influence the population of the medfly such as a very mild winter, and host availability, which may give rise to large population differences among years. This is not uncommon in insect populations and particularly in fruit flies (Diptera: Tephritidae). Interestingly, the performance of the two attractants was similar under low and high population densities, early and late in season.

The attractive components of Biodelear for Tephritids are derived through the Maillard reaction between urea and fructose under specific conditions [44]. One of the main precursors of the Maillard reaction, and a constituent of Biodelear, is the compound pyranone ((+/-)-2, 3-Dihydro-3, 5-dihydroxy-6-methyl-4(H)-pyran-4-one) [51]. This compound, either alone or in combination with other compounds, is probably responsible for the selectivity of Biodelear for $C$. capitata females. Strong evidence for this was provided in a recent study by Mavraganis et al. [52] in which bodies of male Mediterranean fruit flies were extracted with diethyl ether or methanol and subjected to gas chromatography-mass spectrometry. Analysis revealed substantial quantities of pyranone and other hitherto unreported volatile compounds in both wild and laboratory males. In laboratory tests these extracts were found to attract virgin females. Furthermore, in a citrus orchard, traps baited with extracts of wild males, or blends of compounds from males, including pyranone, displayed substantial attractiveness to virgin females compared to control traps [43].

The Maillard reaction, a non-enzymatic reaction between amino acids and reducing sugars $[53,54]$, has been extensively studied in the thermal treatment of foodstuffs, during which browning effects are caused due to the formation of various aromatic compounds along with melanoidins. Melanoidins are nitrogen-containing, amorphous (i.e., with no regular structure and no specific molecular weight) polymeric substances, which have an intense brown colour and are frequently exploited in food technology. In foodstuff preparation, through oxidation procedures, melanoidins and simple aromatic compounds of low molecular weight and organoleptic properties are formed [55-58]. Likewise, in the Maillard reaction between urea and fructose during the manufacturing of Biodelear, 
aromatic compounds of low molecular weight are formed. These compounds are released over several weeks under field conditions and attract insects. The products are considered non-toxic to humans and to the environment since they have been used extensively in the food industry. It must also be noted that these products have been patented for use as feedstuffs for animals such as ruminants [59-61].

The search for effective fruit fly attractants has been an area of intensive research for several decades. The control of C. capitata has historically relied on pesticides, which are currently avoided for their toxicological effects on the environment. At present, bait stations as part of lure and kill control techniques are in demand for the control of medfly as an alternative to standard insecticide sprays [42]. Such methods could easily be combined with biological control, the sterile insect technique, integrated pest management and other control methods with reduced negative impact on the environment. Either alone or in conjunction with these other methods, lure and kill (i.e., mass trapping) control techniques could be a powerful tool in the control of fruit flies and drastically diminish over-reliance on insecticides.

Usually, a large number of traps or bait stations are required per hectare rendering the cost of these control methods an important issue in developing countries and worldwide [62]. Based on the price of urea and fructose in the international market (Alibaba 22 January 2022), the cost of the 17 gr of Biodelear required per trap is less than $€ 0.03$. On the other hand, the cost of Biolure in the Greek market is $€ 5.085$ per dispenser. An extensive economic analysis on the prospective use of Biodelear in citrus cultivations revealed the cost of mass trapping per 0.1 ha per year would be $€ 30$ if ten traps were used with the attractant being replaced five times during the season. The recommended trap density for mass trapping with Biolure would be seven traps per 0.1 ha serviced three times during the season, which amounts to $€ 106.785$ per year [43], which is more than three times that of Biodelear. In the above analyses the cost of the traps was not factored in given that traps can be cleaned and used over several growing seasons.

The performance of Biodelear was high not only when tested in the arboretum of Athens but also in the citrus producing Kampos area of Chios Island from September to December 2015 [45]. These experiments involved mass trapping performed with McPhail traps baited with Biodelear or traps baited with Biolure and resulted in a substantial reduction in the population of $C$. capitata compared to control treatments. Although Biolure initially appeared to be better than Biodelear in mass trapping, later in the season the two attractants converged in efficacy. In both the Biodelear and Biolure treatments, sweet orange and mandarin orange fruits were significantly less infested compared to control treatments. Although these results are rather encouraging, to extract rigorous conclusions on the performance of the attractant Biodelear, additional tests conducted under different population densities and over a variety of climatic conditions need to be conducted.

To investigate if Biodelear also attracts other insects of economic importance, such as the olive fruit fly Bactrocera oleae Rossi, and whether it is selective to bees and safe to predatory and parasitic arthropod species, additionally studies should be performed. Moreover, to maximize its efficacy, Biodelear should be tested with different types of traps to find the ones which best suit the physical and chemical properties of the bait and the behaviour of fruit flies. Its use as a bait spray supplement could also be explored. Besides attracting medflies, Biodelear has been observed in the laboratory to also stimulate feeding by medfly adults [63]. Therefore, the possibility of future exploitation of the new lure as a bait spray supplement is high.

Author Contributions: Conceptualization, V.G.M., N.A.K. and N.T.P.; methodology, V.G.M.; validation, P.D., E.B. and C.S.I.; formal analysis, N.T.P.; investigation, N.A.K., N.T.P., V.G.M., E.B. and D.S.K.; data curation, N.T.P. and V.G.M.; writing-original draft preparation, N.T.P., N.A.K. and V.G.M.; writing-review and editing, N.A.K., N.T.P., V.G.M., E.B., C.S.I., P.D. and D.S.K.; visualization, E.B. and N.T.P.; project administration, N.T.P., E.B., N.A.K. and V.G.M. All authors have read and agreed to the published version of the manuscript. 
Funding: This research was co-funded by the European Union, LIFE+ Environment Policy and Governance, in the context of the project LIFE-BIODELEAR "Addressing Med fly with an innovative and environment friendly attractant through an Integrated Pest Management Strategy", grant number LIFE13 ENV GR/000414.

Data Availability Statement: Will become available upon request.

Acknowledgments: We thank Stavros Vemmos from the Agricultural University of Athens for allowing access to the arboretum for the field bioassays.

Conflicts of Interest: The authors declare no conflict of interest.

\section{References}

1. Broughton, S.; De Lima, C.P.F. Field evaluation of female attractants for monitoring Ceratitis capitata (Diptera: Tephritidae) under a range of climatic conditions and population levels in Western Australia. J. Econ. Entomol. 2002, 95, 507-512. [CrossRef] [PubMed]

2. Damos, P.; Colomar, L.-A.E.; Ioriatti, C. Integrated fruit production and pest management in Europe: The apple case study and how far we are from the original concept? Insects 2015, 6, 626-657. [CrossRef] [PubMed]

3. Alonso-Muñoz, A.; Garcia-Marí, F. Mass-trapping of Ceratitis capitata (Diptera: Tephritidae) in citrus: How it works and factors to improve its efficacy. IOBC WPRS Bull. 2013, 95, 43-50.

4. Katsoyannos, B.I.; Heath, R.R.; Papadopoulos, N.T.; Epsky, N.D.; Hendrichs, J. Field evaluation of Mediterranean fruit fly (Diptera: Tephritidae) female selective attractants for use in monitoring programs. J. Econ. Entomol. 1999, 92, 583-589. [CrossRef]

5. Barclay, H.J.; Li, C. Combining methods of pest control: Minimizing cost during the control program. Theor. Popul. Biol. 1991, 40, 105-123. [CrossRef]

6. Manrakhan, A.; Daneel, J.H.; Beck, R.; Virgilio, M.; Meganck, K.; De Meyer, M. Efficacy of trapping systems for monitoring of Afrotropical fruit flies. J. Appl. Entomol. 2017, 141, 825-840. [CrossRef]

7. Bali, E.-M.D.; Moraiti, C.A.; Ioannou, C.S.; Mavraganis, V.; Papadopoulos, N.T. Evaluation of mass trapping devices for early seasonal management of Ceratitis capitata (Diptera: Tephritidae) populations. Agronomy 2021, 11, 1101. [CrossRef]

8. Hafsi, A.; Rahmouni, R.; Ben Othman, S.; Abbes, K.; Elimem, M.; Chermiti, B. Mass trapping and bait station techniques as alternative methods for IPM of Ceratitis capitata Wiedmann (Diptera: Tephritidae) in citrus orchards. Orient. Insects 2020, 54, 285-298. [CrossRef]

9. Burrack, H.J.; Connell, J.H.; Zalom, F.G. Comparison of olive fruit fly (Bactrocera oleae (Gmelin)) (Diptera: Tephritidae) captures in several commercial traps in California. Int. J. Pest. Manag. 2008, 54, 227-234. [CrossRef]

10. Lasa, R.; Toxtega, Y.; Herrera, F.; Cruz, A.; Navarrete, M.A.; Antonio, S. Inexpensive traps for use in mass trapping Anastrepha ludens (Diptera: Tephritidae). Fla. Entomol. 2014, 97, 1123-1130. [CrossRef]

11. Sampson, C.; Kirk, W.D. Can mass trapping reduce thrips damage and is it economically viable? Management of the western flower thrips in strawberry. PLoS ONE 2013, 8, e80787. [CrossRef]

12. Navarro-Llopis, V.; Vacas, S. Mass trapping for fruit fly control. In Trapping and the Detection, Control, and Regulation of Tephritid Fruit Flies; Springer: Berlin/Heidelberg, Germany, 2014; pp. 513-555.

13. Mertilus, F.; Peña, J.; Ring, D.; Schowalter, T. Inexpensive artisanal traps for mass trapping fruit flies (Diptera: Tephritidae) in Haiti. Fla. Entomol. 2017, 100, 390-395. [CrossRef]

14. Papadopoulos, N.T.; Katsoyannos, B.I.; Carey, J.R.; Kouloussis, N.A. Seasonal and annual occurrence of the Mediterranean fruit fly (Diptera: Tephritidae) in Northern Greece. Ann. Entomol. Soc. Am. 2001, 94, 41-50. [CrossRef]

15. Carey, J.R. Establishment of the Mediterranean fruit fly in California. Science 1991, 253, 1369-1373. [CrossRef]

16. Liquido, N.J.; Shinoda, L.A.; Cunningham, R.T. Host plants of the Mediterranean fruit fly (Diptera, Tephritidae) an annotated world review. Entomol. Soc. Am. 1991, 83, 1863-1878.

17. Carey, J.R. The Mediterranean Fruit Fly (Ceratitis capitata). Am. Entomol. 2010, 56, 116-121. [CrossRef]

18. Liquido, N.J.; Cunningham, R.T.; Nakagawa, S. Host plants of Mediterranean fruit fly (Diptera: Tephritidae) on the Island of Hawaii (1949-1985 survey). J. Econ. Entomol. 1990, 83, 1863-1878. [CrossRef]

19. Malacrida, A.R.; Gomulski, L.M.; Bonizzoni, M.; Bertin, S.; Gasperi, G.; Gugliclmino, C.R. Globalization and fruitfly invasion and expansion: The medfly paradigm. Genetica 2007, 131, 1-9. [CrossRef] [PubMed]

20. Diamantidis, A.D.; Papadopoulos, N.T.; Nakas, C.T.; Wu, S.; Müller, H.G.; Carey, J.R. Life history evolution in a globally invading tephritid: Patterns of survival and reproduction in medflies from six world regions. Biol. J. Linn. Soc. 2009, 97, 106-117. [CrossRef]

21. De Meyer, M.; Robertson, M.P.; Peterson, A.T.; Mansell, M.W. Ecological niches and potential geographical distributions of Mediterranean fruit fly (Ceratitis capitata) and Natal fruit fly (Ceratitis rosa). J. Biogeogr. 2008, 35, 270-281. [CrossRef]

22. Papadopoulos, N.T.; Plant, R.E.; Carey, J.R. From trickle to flood: The large-scale, cryptic invasion of California by tropical fruit flies. Proc. R. Soc. B Biol. Sci. 2013, 280, 1768. [CrossRef] [PubMed]

23. Papadopoulos, N.T. Fruit fly invasion: Historical, biological, economic aspects and management. In Trapping and the Detection, Control, and Regulation of Tephritid Fruit Flies; Springer: Berlin/Heidelberg, Germany, 2014; pp. 219-252.

24. Katsoyannos, B.I. Evaluation of Mediterranean fruit-fly traps for use in sterile-insect-technique programmes. J. Appl. Entomol. 1994, 118, 442-452. [CrossRef] 
25. Epsky, N.D.; Hendrichs, J.; Katsoyannos, B.I.; Vasquez, L.A.; Ros, J.P.; Zumreoglu, A.; Pereira, R.; Bakri, A.; Seewooruthun, S.I.; Heath, R.R. Field evaluation of female-targeted trapping systems for Ceratitis capitata (Diptera: Tephritidae) in seven countries. J. Appl. Entomol. 1999, 92, 156-164. [CrossRef]

26. Katsoyannos, B.I.; Papadopoulos, N.T.; Heath, R.R.; Hendrichs, J.; Kouloussis, N.A. Evaluation of synthetic food-based attractants for female Mediterranean fruit flies (Dipt., Tephritidae) in McPhail type traps. J. Appl. Entomol. 1999, 123, 607-612. [CrossRef]

27. Heath, R.R.; Epsky, N.D.; Midgarden, D.; Katsoyannos, B.I. Efficacy of 1,4-diaminobutane (Putrescine) in a food-based synthetic attractant for capture of Mediterranean and Mexican fruit flies (Diptera: Tephritidae). J. Appl. Entomol. 2004, 97, 1126-1131. [CrossRef]

28. Katsoyannos, B.I.; Papadopoulos, N.T. Evaluation of synthetic female attractants against Ceratitis capitata (Diptera: Tephritidae) in sticky coated spheres and McPhail type traps. J. Appl. Entomol. 2004, 97, 21-26.

29. Mazor, M.; Gothilf, S.; Galun, R. The role of ammonia in the attraction of females of the Mediterranean fruit fly to protein hydrolysate baits. Entomol. Exp. Appl. 1987, 43, 25-29. [CrossRef]

30. Heath, R.R.; Epsky, N.D.; Bloem, S.; Bloem, K.; Acajabon, F.; Guzman, A.; Chambers, D. pH effect on the attractiveness of a corn hydrolysate to the Mediterranean fruit fly and several Anastrepha species (Diptera: Tephritidae. J. Econ. Entomol. 1994, 87, 1008-1013. [CrossRef]

31. Beroza, M.; Green, N.; Gertler, S.; Steiner, L.; Miyashita, D. Insect attractants, new attractants for the Mediterranean fruit fly J. Agric. Food Chem. 1961, 9, 361-365. [CrossRef]

32. Howell, J.; Cheikh, M.; Harris, E. Comparison of the efficiency of three traps for the Mediterranean fruit fly baited with minimun amounts of trimedlure. J. Econ. Entomol. 1975, 68, 277-279. [CrossRef]

33. Leonhardt, B.; Rice, R.; Harte, E.; Cunningham, R. Evaluation of dispensers containing trimedlure, the attractant for the Mediterranean fruit fly (Diptera: Tephritidae). J. Econ. Entomol. 1984, 77, 744-749. [CrossRef]

34. Heath, R.R.; Epsky, N.D.; Dueben, B.D.; Meyer, W.L. Systems to monitor and suppress Ceratitis capitata (Diptera: Tephritidae) populations. Fla. Entomol. 1996, 144-153. [CrossRef]

35. Heath, R.R.; Epsky, N.D.; Dueben, B.D.; Rizzo, J.; Jeronimo, F. Adding methyl-substituted ammonia derivatives to a food-based synthetic attractant on capture of the Mediterranean and Mexican fruit flies (Diptera: Tephritidae). J. Econ. Entomol. 1997, 90, 1584-1589. [CrossRef]

36. Papadopoulos, N.T.; Katsoyannos, B.I.; Kouloussis, N.A.; Hendrichs, J.; Carey, J.R.; Heath, R.R. Early detection and population monitoring of Ceratitis capitata (Diptera: Tephritidae) in a mixed-fruit orchard in Northern Greece. J. Econ. Entomol. 2001, 94, 971-978 [CrossRef] [PubMed]

37. Papadopoulos, N.T.; Katsoyannos, B.I.; Nestel, D. Spatial autocorrelation analysis of a Ceratitis capitata (Diptera: Tephritidae) adult population in a mixed deciduous fruit orchard in northern Greece. Environ. Entomol. 2003, 32, 319-326. [CrossRef]

38. Mediouni Ben Jemâa, J.; Bachrouch, O.; Allimi, E.; Dhouibi, M. Field evaluatin of Mediterranean fruit fly mass trapping with Tripack as alternative to malathion bait-spraying in citrus orchards. Span. J. Agric. Res. 2010, 8, 400-408. [CrossRef]

39. Peñarrubia-María, I.E.; Quilici, S.; Schmitt, C.; Escudero-Colomar, L.A. Evaluation of candidate systems for mass trapping against Ceratitis spp. on La Réunion island. Pest Manag. Sci. 2014, 70, 448-453. [CrossRef]

40. Broughton, S.; Rahman, T. Evaluation of lures and traps for male and female monitoring of Mediterranean fruit fly in pome and stone fruit. J. Appl. Entomol. 2017, 141, 441-449. [CrossRef]

41. Navarro-Llopis, V.; Primo, J.; Vacas, S. Bait station devices can improve mass trapping performance for the control of the Mediterranean fruit fly. Pest. Manag. Sci. 2015, 71, 923-927. [CrossRef]

42. Navarro-Llopis, V.; Alfaro, F.; Dominguez, J.; Sanchis, J.; Primo, J. Evaluation of traps and lures for mass trapping of Mediterranean fruit fly in citrus groves. J. Econ. Entomol. 2008, 101, 126-131. [CrossRef] [PubMed]

43. Mavraganis, V.G.; (HAO-DEMETER, Institute of Soil and Water Resources, 14123 Lykovrissi, S. Venizelou 1, Athens, Greece; mavrag1a@otenet.gr). Field Exp. 2010; unpublished work.

44. Mavraganis, V.G. Maillard Reaction Products for Attracting Insects. WO Patent 2012/056257, 3 May 2012.

45. Kouloussis, N.; Papadopoulos, N.; Ioannou, C.; Damos, P.; Koveos, D.; Bempelou, E.; Mavraganis, V. First results on mass trapping of Ceratitis capitata using the new attractant Biodelear. IOBC-WPRS Bull. 2017, 123, 39-42.

46. Holler, T.C.; Peebles, M.; Young, A.; Whiteman, L.; Olson, S.; Sivinski, J. Efficacy of the Suterra biolure individual female fruit fly attractant packages vs. the unipak version. Fla. Entomol. 2009, 92, 667-669.

47. Kottek, M.; Grieser, J.; Beck, C.; Rudolf, B.; Rubel, F. World Map of the Koppen-Geiger climate classification updated. Meteorol. Z. 2006, 15, 259-263. [CrossRef]

48. Zervas, G.; Kateva, A.X.; Christopoulos, A. Ways of overwintering of medfly Ceratitis capitata (Wied.) (Dipt.: Tephritidae). The overwintering of larvae suspended fruits of citrus trees in Attica, Greece. In Proceedings of the V Panhellenic Entomological Congress, Athens, Greece, 6-8 November 1985; pp. 8-10.

49. Katsoyannos, B.I.; Kouloussis, N.A.; Carey, J.R. Seasonal and annual occurrence of Mediterranean fruit flies (Diptera: Tephritidae) on Chios island, Greece: Differences between two neighboring citrus orchards. Ann. Entomol. Soc. Am. 1998, 91, 43-51. [CrossRef]

50. IAEA. Trapping Guidelines for Area-Wide Fruit Fly Programmes; IAEA/FAO-TG/FFP; IAEA: Vienna, Austria, 2003.

51. Kim, M.O.; Baltes, W. On the role of 2, 3-dihydro-3, 5-dihydroxy-6-methyl-4 (H)-pyran-4-one in the Maillard reaction. J. Agric. Food Chem. 1996, 44, 282-289. [CrossRef]

52. Mavraganis, V.; Liaropoulos, C.; Papadopoulos, N.; Kouloussis, N.; Broumas, T. Whole body extract of Mediterranean fruit fly males elicits high attraction in virgin females. Entomol. Exp. Appl. 2008, 127, 20-29. [CrossRef] 
53. Maillard, L. Action of amino acids on sugars. Formation of melanoidins in a methodical way. Compt. Rend. 1912, 154, 66-68.

54. Hodge, J.E. Dehydrated foods, chemistry of browning reactions in model systems. J. Agric. Food Chem. 1953, 1, 928-943. [CrossRef]

55. Fogliano, V.; Maria Monti, S.; Musella, T.; Randazzo, G.; Ritieni, A. Formation of coloured Maillard reaction products in a gluten-glucose model system. Food Chem. 1999, 66, 293-299. [CrossRef]

56. Hofmann, T.; Czerny, M.; Calligaris, S.; Schieberle, P. Model studies on the Influence of coffee melanoidins on flavor volatiles of coffee beverages. J. Agric. Food Chem. 2001, 49, 2382-2386. [CrossRef]

57. Hofmann, T.; Schieberle, P. Chemical Interactions between odor-active thiols and melanoidins involved in the aroma staling of coffee beverages. J. Agric. Food Chem. 2001, 50, 319-326. [CrossRef] [PubMed]

58. Obretenov, C.; Demyttenaere, J.; Tehrani, K.A.; Adams, A.; Keršiene, M.; De Kimpe, N. Flavor release in the presence of melanoidins prepared from 1-(+)-ascorbic acid and amino acids. J. Agric. Food Chem. 2002, 50, 4244-4250. [CrossRef] [PubMed]

59. Elwakeel, E.; Titgemeyer, E.; Drouillard, J.; Armendariz, C. Evaluation of ruminal nitrogen availability in liquid feeds. Anim. Feed Sci. Technol. 2007, 137, 163-181. [CrossRef]

60. Thomas, M.C.; Forbes, J. The Maillard Reaction: Interface between Aging, Nutrition and Metabolism; Royal Society of Chemistry: London, UK, 2010; Volume 322.

61. Drouillard, J.S.; Coetzer, C.M. Method of Manufacturing a Ruminant Feedstuff with Reduced Ruminal Protein Degradability. U.S. Patent 6,506,423, 14 January 2003.

62. Martinez-Ferrer, M.T.; Campos, J.M.; Fibla, J.M. Field efficacy of Ceratitis capitata (Diptera: Tephritidae) mass trapping technique on clementine groves in Spain. J. Appl. Entomol. 2012, 136, 181-190. [CrossRef]

63. Papadopoulos, N.T.; (Laboratory of Entomology and Agricultural Zoology, Department of Agriculture Crop Production and Rural Environment, University of Thessaly, Phytokou St. 38436 N. Ionia (Volos) Greece; nikopap@uth.gr). Laboratory Experiments, 2018; unpublished work. 